\title{
Information Sciences
}

National Cancer Institute

\section{Source}

National Cancer Institute. Information Sciences. NCI Thesaurus. Code C16733.

The sciences concerned with gathering and manipulating and storing and retrieving and classifying recorded information. 